\title{
Comparison of deconvoluted plasma DSC curves on patients with solid tumors
}

\author{
Dénes Lőrinczy ${ }^{1} \cdot$ Andrea Ferencz $^{2}$
}

Received: 2 August 2019 / Accepted: 11 February 2020 / Published online: 18 March 2020

(c) The Author(s) 2020

\begin{abstract}
Today, differential scanning calorimetry (DSC) has increasingly been an accepted method for diagnosing and monitoring different diseases. Moreover, as a highly sensitive technique it seems to be applicable in human cancer researches. Our workgroup in several previous researches has already demonstrated marked differences on DSC plasma profiles between healthy control and various tumorous patients and, in addition, at their different stages. The aim of this study was to compare deconvoluted plasma DSC curves on patients with solid tumors. Blood plasma DSC data were analyzed retrospectively from various patients, who has only local cancer diseases (malignant melanoma: $n=15$, breast carcinoma: $n=10$ and pancreas adenocarcinoma: $n=11$ ) without any regional or distant metastases. The complex curves were deconvoluted in numerous individual transitions (five or seven melting points). In the examined patients with solid tumors, the thermodynamic parameters: heat flow and calorimetric enthalpy of the transitions corresponding to the most abundant plasma proteins, as well as the numbers of transitions were determined from the calorimetric profiles. Deconvoluted DSC curves from blood samples of patients showed differences and similarities at the same time in the thermal denaturation of plasma components in various carcinoma cases.
\end{abstract}

Keywords Solid tumors $\cdot$ Blood plasma $\cdot$ DSC $\cdot$ Curve $\cdot$ Deconvolution

\section{Introduction}

According to the survey of World Health Organization (WHO), cancer is the second leading cause of death globally and is responsible for an estimated 9.6 million deaths in 2018 [1]. Based on the WHO GLOBOCAN (Global Cancer) database, breast cancer is the third, melanoma malignum (MM) is the fifth, while pancreas adenocarcinoma is the twelfth in terms of incidence and these malignant diseases are ranked within the top twenty in terms of mortality [2]. Basically, these solid tumors have two major types of groups: sarcomas and carcinomas. Many types of solid

Andrea Ferencz

andrea.ferencz@gmail.com

Dénes Lőrinczy

denes.lorinczy@pte.hu

1 Institute of Biophysics, Medical School, University of Pécs, Pecs, Szigeti Str. 12, Hungary

2 Department of Surgical Research and Techniques, Medical Faculty, Semmelweis University, Budapest, Nagyvárad Sqr. 4, 1089, Hungary tumors are often treated with surgery. But, next to the type and stage of tumors during treatment decision making for cancer takes into account risks contra benefits of planned therapy, and treatment should be supplemented with postoperative chemo- and/or radiotherapy, or with targeted biological treatment or multimodal therapy if these are available for that cancer type [3].

Blood samples examination is still a noninvasive detection and monitoring method during cancer research and patient care also. Today, among the features that can be detected in blood only the tumor markers are suitable partly for diagnosis and partly for monitoring. These are gene products which signal the occurrence of tumors in different organs as well as their response to surgery and to preoperative (neoadjuvant) or postoperative (adjuvant) therapy [4]. The first discovered tumor marker was alpha-fetoprotein (AFP) in 1956, followed by carcinoembryonic antigen (CA) in 1965. Since then, many different tumor markers have been characterized and are in clinical use. But, no "universal" marker in the blood has been found that can reveal the presence of any type of cancer. Tumor markers have traditionally been proteins or other substances that are made by both 
normal and cancer cells, but at higher amounts by cancer cells [5]. The other and new area of cancer research is, for example, using circulating tumor DNA with many considerable implications in clinical management. The main question is always the specificity and sensitivity of a given measurement method [6].

It seems for us that in the last 60-70 years, research of blood tests has not brought the breakthrough in diagnosing and monitoring of tumors. In the last 10 years, many our research and previous studies from others have highlighted the potential applicability of the DSC technique in the diagnosis of certain tumors [7-11]. After positive results of the first experiments to elucidate the clinical utility of DSC, it is important to establish the sensitivity and specificity of the method. Moreover, it is important to examine the content elements of the data, to summarize the consequences of the measurements and finally to identify the individual parts of complex curves of the DSC curves. In the present study, our goal was to compare deconvoluted plasma DSC curves on patients with newly diagnosed, operable and metastasis-free solid tumors.

\section{Materials and methods}

\section{Patient selection}

Thirty-six patients ( 19 women and 17 men, aged from 22 to 71 years) were involved in recent study; mean age was $50.9 \pm 8.2$ years. Ten age- and sex-matched healthy persons with a mean age of $45.1 \pm 4.7$ were selected as controls. Patients had newly diagnosed operable skin cancer $(n=15)$ or breast cancer $(n=10)$ or pancreas tumor $(n=11)$ without any distant metastases. After cancer removal and histopathological evaluation of the specimen, histology confirmed the malignant lesions, namely malignant melanoma, invasive breast carcinoma and pancreas adenocarcinoma. Moreover, measurements of tumor propagation verified the only local tumor diagnosis. Blood samples were collected at the beginning of surgery, and until then, nobody was given any antitumor treatment (chemo- or radio- or biological therapy). Patients were operated in profession-specific units of University of Pécs (Department of Dermatology, Venereology and Oncodermatology; Department of Surgery). The study protocol was approved by regional ethical committee of University of Pécs.

\section{Blood sample collection and preparation}

Peripheral blood samples were collected from patients $(n=36)$ and from healthy individuals $(n=10)$. Blood samples were collected into the Vacutainer tubes containing EDTA $\left(1.5 \mathrm{mg} \mathrm{mL}^{-1}\right.$ of blood) centrifuged at $1.600 \mathrm{~g}$ for
15 min at $4{ }^{\circ} \mathrm{C}$ to separate plasma fraction from cell components. Native plasmas were stored at $-80{ }^{\circ} \mathrm{C}$ until DSC measurement.

\section{Calorimetric measurement}

The thermal unfolding of the human plasma components was monitored by SETARAM Micro DSC-II calorimeter as previously described [12]. In brief, all experiments were conducted between 0 and $100{ }^{\circ} \mathrm{C}$. The heating rate was $0.3 \mathrm{~K} \mathrm{~min}^{-1}$ in all cases. Conventional Hastelloy batch vessels were used during the denaturation experiments with 850 $\mu \mathrm{L}$ sample volume in average. Reference sample was normal saline $(0.9 \% \mathrm{NaCl})$. The sample and reference samples were equilibrated with a precision of $\pm 0.1 \mathrm{mg}$. The repeated scan of denatured sample was used as baseline reference, which was subtracted from the original DSC curve. We have plotted the heat flow (DSC-II is a heat flux instrument with hermetically closed vessels) as a function of temperature. Calorimetric enthalpy was calculated from the area under the heat flow curve by using two-point setting SETARAM peak integration.

\section{Deconvolution of DSC thermal curve}

The plasma is a complex protein mixture. Therefore, it contains from a thermal point of view different "thermal domains" which can be assigned to the different compounds $[7,8,13]$. It means that a DSC scan can be decomposed into a sum of Gaussian curves that way that their total area is the same as of the experimental curve one, within a reasonable error $(<1 \%)$. To have the best fitting we applied more than five curves, but some contribution was less than the error of enthalpy determination, so they were omitted because cannot influence our final interpretation of data.

\section{Statistical analysis}

All results are given in mean values \pm standard error of the mean (SEM). In the case of deconvoluted curves, those thermal transitions where the enthalpy contribution was around the error of the determination of total calorimetric enthalpy are omitting from the evaluation (e.g., signing them on deconvoluted curves).

\section{Results}

The average main thermal curves (black line) were deconvoluted and usually exhibited five to seven separable components (colored lines, fitting curve is red). The order of appearance of each component in the case of seven transition temperatures was green, blue, pink, dark yellow, navy, 


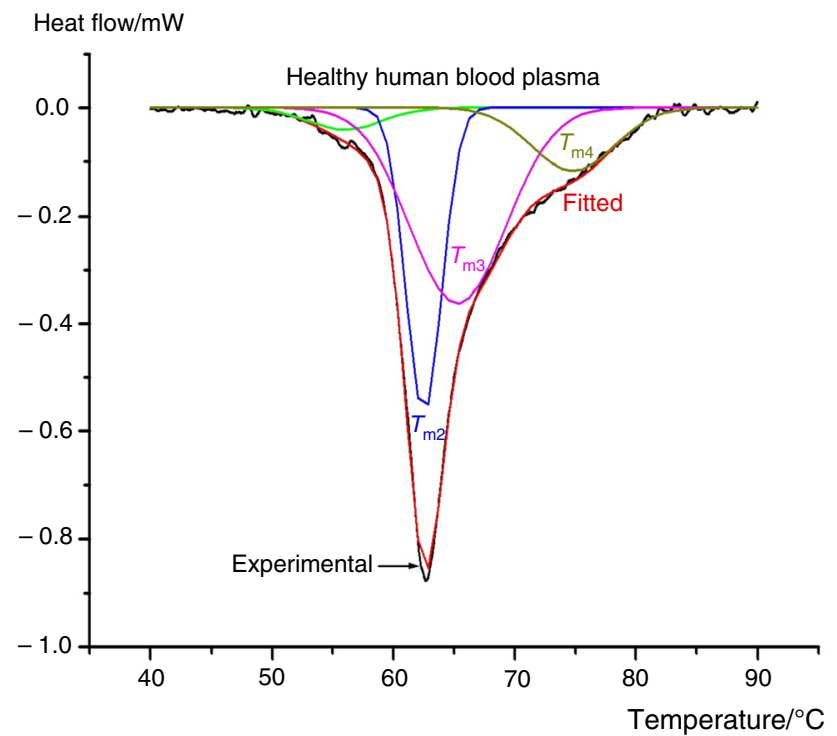

Fig. 1 DSC curve of average healthy blood plasma (black line) and its deconvoluted thermal domains (with different colors). The fitted curve is in red. All the important transition temperatures are marked, and the endotherm process is directed downwards in all figures

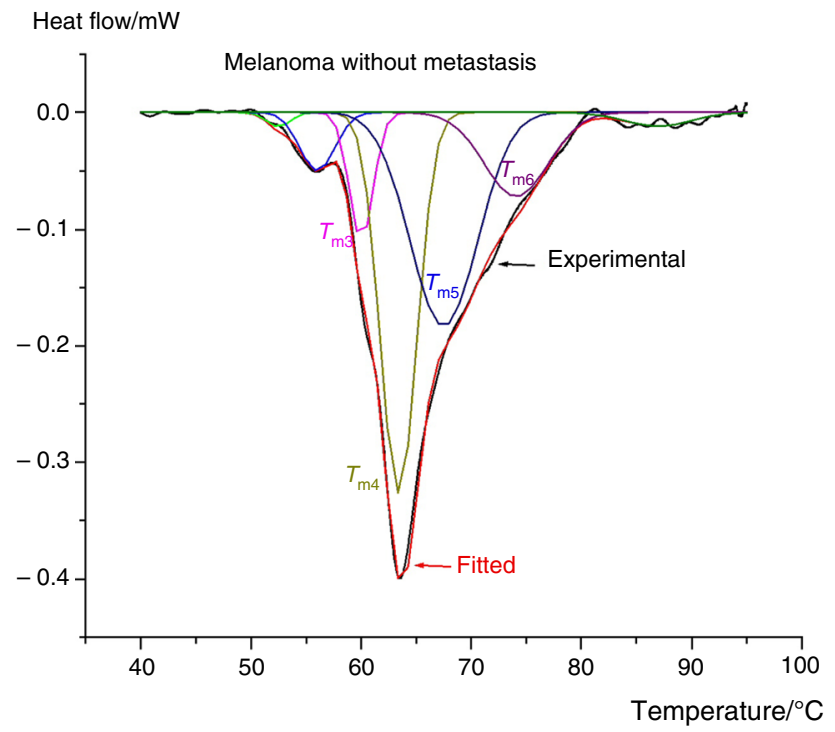

Fig. 2 Average DSC thermal curves and deconvoluted blood plasma components show melting points and thermal transitions on patients with local melanoma malignum cancer

purple and brown. Presently, the results of blood plasma deconvoluted curves of healthy patients are shown in Fig. 1, the melanoma malignum in Fig. 2, breast cancer in Fig. 3 and operable malignant pancreas adenocarcinoma in Fig. 4. According to the literature data, the next plasma compounds can be identified using the thermal denaturation of each compound isolated by electrophoresis: in temperature range $48-58{ }^{\circ} \mathrm{C}$ fibrinogen, around $63{ }^{\circ} \mathrm{C}$ albumin (the main
Heat flow $/ \mathrm{mW}$

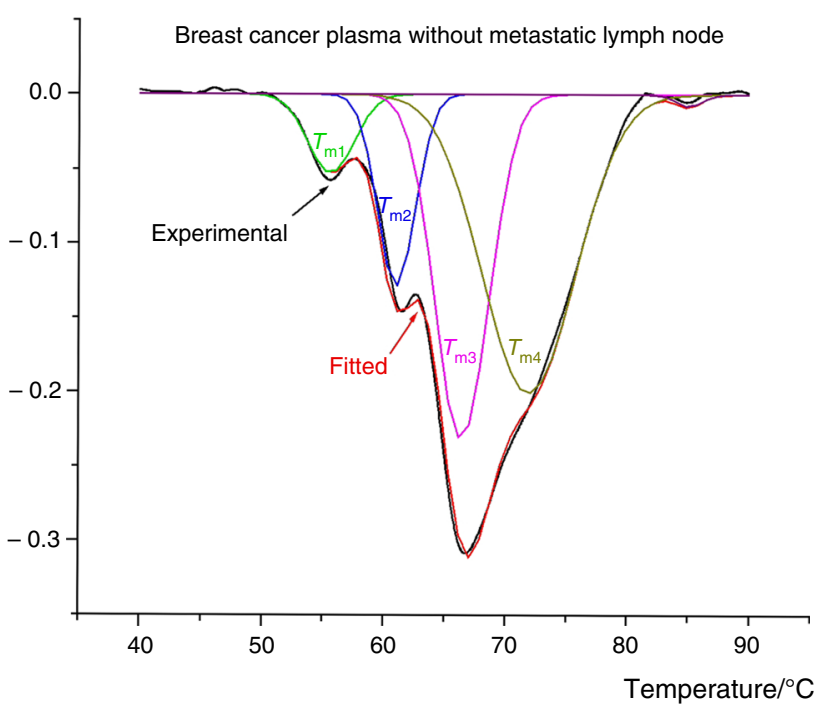

Fig. 3 DSC thermal changes and deconvoluted blood plasma components on patients with breast cancer without metastatic lymph node complication

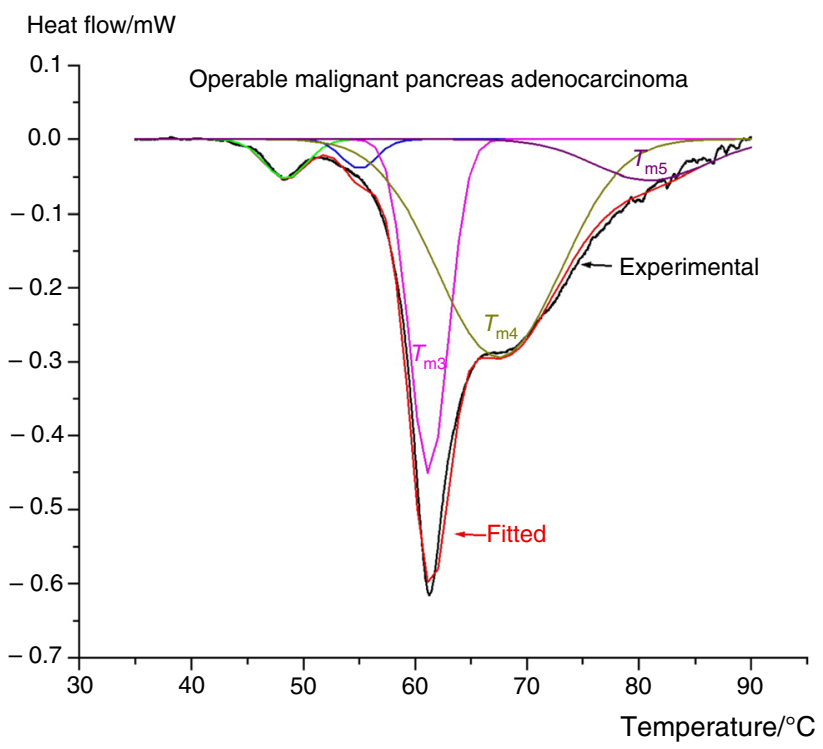

Fig. 4 Human blood plasma DSC curves and its deconvoluted components after malignant, but operable pancreas adenocarcinoma

constituent of plasma), $\sim 70{ }^{\circ} \mathrm{C}$ mainly immunoglobulins (Ig), albumin's minor and tail transition. The complement protein $\mathrm{C} 3$, IgA and albumin can appear at $\sim 76{ }^{\circ} \mathrm{C}$, and in some cases, a contribution can be identified around $82{ }^{\circ} \mathrm{C}$ from IgG and transferrin [7, 8]. As Table 1 shows, the total calorimetric enthalpies $\left(H_{\mathrm{T}}\right)$ decreased in the three disease group compared to values of healthy volunteers. The contribution of fibrinogen in calorimetric enthalpy was in the 
Table 1 Melting temperatures and calorimetric enthalpies of human blood plasma in healthy individuals and in patients who have been operated with different solid tumors (transition temperature: $T_{\mathrm{m}}{ }^{\circ} \mathrm{C}$ for influenced thermal domain)

\begin{tabular}{|c|c|c|c|c|c|c|c|c|}
\hline \multirow[t]{2}{*}{ Groups } & \multicolumn{8}{|c|}{ Thermal parameters } \\
\hline & $\begin{array}{l}T_{\mathrm{ml}} /{ }^{\circ} \mathrm{C} \Delta H / \\
\mathrm{Jg}^{-1}\end{array}$ & $\begin{array}{l}T_{\mathrm{m} 2} /{ }^{\circ} \mathrm{C} \Delta H / \\
\mathrm{Jg}^{-1}\end{array}$ & $\begin{array}{l}T_{\mathrm{m} 3}{ }^{\circ} \mathrm{C} \Delta H / \\
\mathrm{Jg}^{-1}\end{array}$ & $\begin{array}{l}T_{\mathrm{m} 4} /{ }^{\circ} \mathrm{C} \Delta H / \\
\mathrm{Jg}^{-1}\end{array}$ & $\begin{array}{l}T_{\mathrm{m} 5} /{ }^{\circ} \mathrm{C} \Delta H / \\
\mathrm{Jg}^{-1}\end{array}$ & $\begin{array}{l}T_{\mathrm{m} 6} /{ }^{\circ} \mathrm{C} \Delta H / \\
\mathrm{Jg}^{-1}\end{array}$ & $\begin{array}{l}T_{\mathrm{m} 7} /{ }^{\circ} \mathrm{C} \Delta H / \\
\mathrm{Jg}^{-1}\end{array}$ & $\Delta H_{\mathrm{T}} / \mathrm{Jg}^{-1}$ \\
\hline \multirow{2}{*}{$\begin{array}{l}\text { Healthy } \\
\text { control }\end{array}$} & 56.0 & 62.5 & 65.3 & 74.8 & - & - & - & \\
\hline & 0.04 & 0.39 & 0.70 & 0.17 & & & & $1.29 \pm 0.06$ \\
\hline \multirow{2}{*}{$\begin{array}{l}\text { Melanoma } \\
\text { malignum } \\
(n=15)\end{array}$} & 52.5 & 56 & 60 & 63.4 & 67.5 & 74.1 & 87 & \\
\hline & 0.01 & 0.06 & 0.09 & 0.39 & 0.41 & 0.16 & 0.026 & $1.14 \pm 0.05$ \\
\hline \multirow{2}{*}{$\begin{array}{l}\text { Breast cancer } \\
\quad(n=10)\end{array}$} & 55.6 & 61 & 66.4 & 71.9 & 85 & - & - & \\
\hline & 0.07 & 0.15 & 0.38 & 0.56 & 0.01 & & & $1.16 \pm 0.05$ \\
\hline \multirow{2}{*}{$\begin{array}{l}\text { Pancreas ade- } \\
\text { nocarcinoma } \\
(n=11)\end{array}$} & 48.4 & 55 & 61.2 & 67.5 & 81 & - & - & \\
\hline & 0.05 & 0.03 & 0.36 & 0.74 & 0.13 & & & $1.3 \pm 0.06$ \\
\hline
\end{tabular}

Calorimetric enthalpy: $\Delta H / \mathrm{Jg}^{-1}$ for convoluted curves, $\Delta H_{\mathrm{T}} / \mathrm{Jg}^{-1}$ for average of DSC scans with average $\pm \mathrm{SD}$

Italic values indicate significant difference compared with healthy control

range of enthalpy determination error $(\sim 5 \%)$, and in the case of MM and pancreas adenoma, it exhibited two separable thermal domains (see Table 1). The transition-giving albumin's melting point (in our healthy sample $T_{\mathrm{m} 2}=62.5^{\circ} \mathrm{C}$ ) at MM stage increased to $T_{\mathrm{m} 4}=63.4{ }^{\circ} \mathrm{C}$ with unchanged enthalpy, while in breast cancer and pancreas carcinoma it decreased to $T_{\mathrm{m} 2}=61{ }^{\circ} \mathrm{C}$ as well as to $T_{\mathrm{m} 3}=61.2^{\circ} \mathrm{C}$. The calorimetric enthalpy decreased significantly only in the case of breast cancer. The contribution of immunoglobulins (Ig) + albumin's minor and tail transition (exhibited in the control at $65.3^{\circ} \mathrm{C}$ ) gave the highest enthalpy contribution in all samples, but $T_{\mathrm{m}}$ shifted up for MM to 67.5, in breast cancer to 66.4 and for pancreas tumor to $67.5^{\circ} \mathrm{C}$. The transition exhibited by complements and immunoglobulins showed the next changes; $T_{\mathrm{m} 4}=74.8^{\circ} \mathrm{C}$ control, $T_{\mathrm{m} 6}=74.1^{\circ} \mathrm{C}$ for $\mathrm{MM}$, $T_{\mathrm{m} 4}=71.9^{\circ} \mathrm{C}$ in the case of breast cancer and $T_{\mathrm{m} 5}=81{ }^{\circ} \mathrm{C}$ for pancreas sample (see Table 1 and Figs. 1-4). The calorimetric enthalpy, as an indicator of overall thermal stability of the whole system, showed a decreasing tendency in patients with $\mathrm{MM}$ and breast cancer compared to controls (1.29 $\mathrm{Jg}^{-1}$ versus $1.14 \mathrm{Jg}^{-1}$ and $1.16 \mathrm{Jg}^{-1}$ ).

\section{Discussion}

Recently, the plasma proteome and peptidome still hold great promise for disease diagnosis and therapeutic monitoring. Interestingly, according to a validated method, mass spectrometry-based approach showed significant changes in low-abundance proteins and peptides in blood plasma. In contrast, in other studies, for example, nuclear magnetic resonance, electrophoresis and immunochemistry are widely applied to monitor the level of most abundant plasma proteins to provide important information for disease detection and monitoring [14]. Knowing the different literature data, in several previous studies of our research group, we showed some "cancer-specific" changes which occur in the most abundant protein mass of the human blood plasma. Seeing different results and finding solutions no doubt, there is a constant need for new methods and technologies to provide reliable early detection a disease, particularly tumors and monitor patients with a noninvasive manner.

It has already been confirmed in several publications by each research group that during denaturation of blood plasma components the "cumulative" DSC curve can be broken down into 5-6 sub-curves containing same number transition temperatures (melting points) [7, 8, 13-15]. With this, deconvolution processes could be shown that mostly the thermodynamics of main plasma proteins are changed. Similarly, our previous investigations showed permanent appearance of plasma thermal changes also [9-12]. In fact, these observations are true for not only individual disease groups, but also in known malignant symptoms and in its different severity stages. The trend of changes-among the first-has prompted our research team to examine what components are behind the summarized curves and how these are changing.

Previous research works recorded that DSC average plasma profile from healthy individuals can be separated by five transitions at about $56{ }^{\circ} \mathrm{C}, 62{ }^{\circ} \mathrm{C}, 65^{\circ} \mathrm{C}, 74^{\circ} \mathrm{C}$ and $82{ }^{\circ} \mathrm{C}[7,8,13] . T_{\mathrm{m} 1}$ transition can be attributed mainly to fibrinogen, $T_{\mathrm{m} 2}$ to albumin, $T_{\mathrm{m} 3}$ to immunoglobulins and albumin minor tail, $T_{\mathrm{m} 4}$ to complement protein C3, IgA, IgG and finally $T_{\mathrm{m} 5}$ to one part of IgG and transferrin. Although the DSC data from our study reveal heterogeneity in the scans, some common characteristics for the plasma profiles majority were observable. 
In this report were studied human blood plasma samples from healthy controls and patients with diagnosed skin or breast or pancreas carcinomas without any distal metastases. The scans from healthy subjects were clearly different from those corresponding to solid tumors patients. Furthermore, deconvoluted plasma scans showed similar tendency in thermal parameters: (1) transition temperatures decreased in near all cases and tumor types, (2) new transition temperatures appeared in a higher (up to $70{ }^{\circ} \mathrm{C}$ ) temperature range and (3) the calorimetric enthalpy, as an indicator of overall thermal stability of the whole system, showed a decreasing tendency in patients. Looking at the international literature, we found that present results can be considered as novel because there are no other results describing such blood plasma changes with thermoanalytical method on patients who have any solid tumor. Several research groups have been investigated blood plasma changes in patients yet who are treated for cancer, inflammatory disease or other causes [16-20]. But, the most important result is that local solid tumors can cause consistently early difference in plasma protein composition and these changes are detectable by deconvolution of DSC scans.

According to our knowledge, this is a first research that shows the solid tumor influences on the plasma composition. But, according to our hypothesis these transition temperatures changes; not only numerical changes but also qualitative changes may be responsible for the dramatic changes in melting temperatures. Other researchers explained these results, on the one hand, with conformational changes or protein modifications, while the others with specific interactions between small and most abundant proteins [21, 22].

This work showed average thermal changes and human blood plasma deconvoluted components of patients with solid tumors originated from skin, mammary gland and pancreas tissue. With our current methods and technologies, the detectability of changes is not enough exact, but the constant appearance of changes shows that differences in plasma are consistent. But, we conclude that these changes appeared in a very permanent way not only in each disease group, but also in certain diseases and in their different stages. Nevertheless, modern biocalorimetry can bring new perspectives; thus, modern DSC devices and data evaluation software may also revolutionize the cancer prediction, diagnosis and monitoring in the near future.

Acknowledgements Open access funding provided by Semmelweis University (SE). This research was funded by grant OTKA (C272 for D.L. and PD77474 for A.F.) and PTE ÁOK Research Grant (114603/2009 for A.F.).

Open Access This article is licensed under a Creative Commons Attribution 4.0 International License, which permits use, sharing, adaptation, distribution and reproduction in any medium or format, as long as you give appropriate credit to the original author(s) and the source, provide a link to the Creative Commons licence, and indicate if changes were made. The images or other third party material in this article are included in the article's Creative Commons licence, unless indicated otherwise in a credit line to the material. If material is not included in the article's Creative Commons licence and your intended use is not permitted by statutory regulation or exceeds the permitted use, you will need to obtain permission directly from the copyright holder. To view a copy of this licence, visit http://creativecommons.org/licenses/by/4.0/.

\section{References}

1. WHO, The International Agency for Research on Cancer. Latest global cancer data: cancer burden rises to 18.1 million new cases and 9.6 million cancer deaths in 2018. Press Release No. 263, Geneva, Switzerland, 12 September 2018.

2. Bray F, Ferlay J, Soerjomataram I, Siegel RL, Torre LA, Jemal A. Global cancer statistics 2018: GLOBOCAN estimates of incidence and mortality worldwide for 36 cancers in 185 countries. CA Cancer J Clin. 2018;68:394-424.

3. Gavhane YN, Shete AS, Bhagat AK, Shinde VR, Bhong KK, Khairnar GA, Yadav AV. Solid tumors: facts, challenges and solutions. Int J Phar Sci Res. 2011;2:1-12.

4. GyM Búzás. History of the development of tumor markers of the digestive tract cancers. Orv Hetil. 2013;154:810-9.

5. Parham DM. Immunohistochemical markers of soft tissue tumors: pathologic diagnosis, genetic contributions, and therapeutic options. Anal Chem Insights. 2015;10(S1):1-10.

6. Aravanis AM, Lee M, Klausner RD. Next-generation sequencing of circulating tumor DNA for early cancer detection. Cell. 2017; 168:571-4.

7. Garbett NC, Mekmaysy C, Helm CV, Jenson AB, Chaires JB. Differential scanning calorimetry of blood plasma for clinical diagnosis and monitoring. Exp Mol Pathol. 2009;86:186-91.

8. Todinova S, Krumova S, Kurtev P, Dimitrov V, Djongov L, Dudunkov Z, Taneva SG. Calorimetry-based profiling of blood plasma from colorectal cancer patients. Biochim Biophys Acta. 2012;1820:1879-85.

9. Ferencz A, Fekecs T, Lőrinczy D. Differential scanning calorimetry as a new method to monitor human plasma in melanoma patients with regional limph node or distal metastases. In: Yaguang X, editor. Skin cancer book. Rijeka: InTech; 2011. p. 141-53.

10. Ferencz A, Lőrinczy D. DSC measurements of blood plasma on patients with chronic pancreatitis and operable and inoperable pancreatic adenocarcinoma. J Therm Anal Calorim. 2017;127:1187-92.

11. Zapf I, Moezzi M, Fekecs T, Nedvig K, Lőrinczy D, Ferencz A. Influence of oxidative injury and monitoring of blood plasma by DSC on breast cancer patients. J Therm Anal Calorim. 2016;123:2029-35.

12. Ferencz A, Moezzi M, Lórinczy D. Differential scanning calorimetry (DSC) as a new diagnostic and screening method on patients with psoriasis. In: Lambert W, editor. Psoriasis: epidemiology, diagnosis and management strategies. New York: Nova Science Publishers; 2016. p. 45-64.

13. Michnik A, Drzazga Z. Thermal denaturation of mixtures of human serum proteins. DSC study. J Therm Anal Calorim. 2010;101:513-8.

14. Michnik A. Blood plasma, serum and serum proteins microcalorimetric studies aimed at diagnosis support. In: Lőrinczy D, editor. Thermal analysis in medical application. Budapest: Akadémiai Kiadó; 2011. p. 171-90. 
15. Ferencz A, Nedvig K, Lórinczy D. DSC examination of the intestinal tissue following ischemic injuries. In: Lőrinczy D, editor. Thermal analysis in medical application. Budapest: Akadémiai Kiadó; 2011. p. 255-69.

16. Michnik A, Drzazga Z, Michalik K, Barczyk A, Santura I, Sozańska E, Pierzchała W. Diferential scanning calorimetry study of blood serum in chronic obstructive pulmonary disease. J Term Anal Calorim. 2010;102:57-60.

17. Kędra-Królik K, Chmielewska I, Michnik A, Zarzycki P. Blood serum calorimetry indicates the chemotherapeutic efficacy in lung cancer treatment. Sci Rep. 2017;7:16796.

18. Vega S, Garcia-Gonzalez MA, Lanas A, Velazquez-Campoy A, Abian O. Deconvolution analysis for classifying gastric adenocarcinoma patients based on differential scanning calorimetry serum thermograms. Sci Rep. 2015;5:7988.
19. Könczöl F, Farkas N. The tumor cured, but what about the patient? Orv Hetil. 2013;154:510-5.

20. Bû́cs G, Nőt LG, Dandé Á, Wiegand N, Lőrinczy D. Detection of joint capsule changes by differential scanning calorimetry (DSC) in different types of hip disorders to evaluate surgical techniques (a preliminary report). J Therm Anal Calorim. 2017;130:1293-6.

21. Garbett NC, Miller JJ, Jenson AB, Miller DM, Chaires JB. Interrogation of the plasma proteome with differential scanning calorimetry. Clin Chem. 2007;53:2012-4.

22. Zhou M, Lucas DA, Chan KC, Issaq HJ, Petricoin EF, Liotta LA, Veenstra TD, Conrads TP. An investigation into the human serum "interactome". Electrophoresis. 2004;25:1289-98.

Publisher's Note Springer Nature remains neutral with regard to jurisdictional claims in published maps and institutional affiliations. 